\title{
Erratum to: Threats to Neurosurgical Patients Posed by the Personal Identity Debate
}

\author{
Sabine Müller • Merlin Bittlinger • Henrik Walter
}

Published online: 30 March 2017

C) Springer Science+Business Media Dordrecht 2017

\section{Erratum to: Neuroethics}

DOI 10.1007/s12152-017-9304-0

Unfortunately, for this published online paper the funding information was missing.

The added funding information is shown below.

Funding Information: German Federal Ministry of Education and Research (01 GP 1621A)

The online version of the original article can be found at http://dx. doi.org/10.1007/s12152-017-9304-0

S. Müller $(\bowtie) \cdot$ M. Bittlinger $\cdot H$. Walter

Department for Psychiatry and Psychotherapy, CCM, Charité Universitätsmedizin Berlin, Charitéplatz 1, 10117 Berlin,

Germany

e-mail: Mueller.Sabine@charite.de 